\title{
Further Fossil finds from Flores
}

\section{Citation}

Lieberman, Daniel E. 2005. Further fossil finds from Flores. Nature 437: 957-958.

\section{Published Version}

doi:10.1038/437957a

\section{Permanent link}

http://nrs.harvard.edu/urn-3:HUL.InstRepos:3743585

\section{Terms of Use}

This article was downloaded from Harvard University's DASH repository, and is made available under the terms and conditions applicable to Other Posted Material, as set forth at http:// nrs.harvard.edu/urn-3:HUL.InstRepos:dash.current.terms-of-use\#LAA

\section{Share Your Story}

The Harvard community has made this article openly available.

Please share how this access benefits you. Submit a story.

\section{Accessibility}




\title{
NEWS \& VIEWS
}

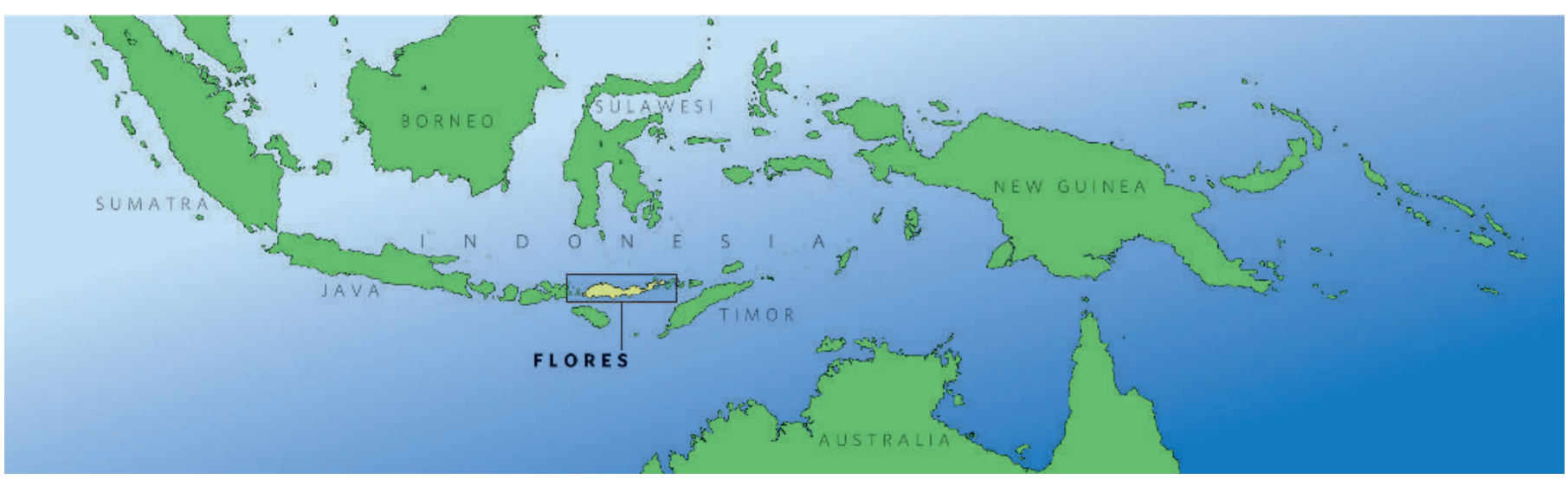

PALAEOANTHROPOLOGY

\section{Further fossil finds from Flores}

\author{
Daniel E. Lieberman
}

\section{New fossil discoveries on Flores, Indonesia, bolster the evidence that Homo floresiensis was a dwarfed human species that lived at the end of the last ice age. But the species' evolutionary origins remain obscure.}

When Gulliver was shipwrecked on the East Indian island of Lilliput in Swift's satirical novel, he was astonished to discover tiny humans. Last year's announcement ${ }^{1,2}$ of a newly discovered species of tiny human from the Indonesian island of Flores was far more astonishing, because it wasn't made up. This intriguing scientific story continues on page 1012 of this issue ${ }^{3}$, where Morwood and colleagues describe further fossil evidence from the cave of Liang Bua on Flores.

The original fossil remains ${ }^{1}$ consisted primarily of a single partial skeleton (LB1), excavated from deposits in Liang Bua dated to the end of the last ice age. Stone tools, evidence of fire-making and the bones of a dwarfed elephant species were also found, those bones apparently being the result of hunting. The LB1 skeleton, dated to 18,000 years ago, was probably a female, just over a metre tall. It had a brain volume of $380 \mathrm{~cm}^{3}$, roughly the size of a chimpanzee brain. Although LB1 has a somewhat primitively shaped pelvis, it shares many derived characteristics of the genus Homo, particularly in the teeth, jaw and cranium. These similarities, combined with other distinctive features, led Brown and colleagues ${ }^{1}$ to propose a new species, Homo floresiensis. They further suggested that $H$. floresiensis was a dwarfed descendant of Homo erectus, another hominid species, which is thought to have arrived on Flores by 800,000 years ago ${ }^{4}$.

Homo floresiensis caused a stir by challenging preconceptions. If it is a new species, then we shared this planet with other hominids much more recently than anyone thought long after the Neanderthals became extinct, after modern humans arrived in Australia, and at about the time that agriculture was first invented. More unusual is the proposal that $H$. floresiensis evolved from $H$. erectus through dwarfing. This phenomenon, known as endemic or island dwarfing, sometimes occurs on islands when species are released from the pressures of predation but become constrained by limited resources and small population sizes ${ }^{5}$. In such conditions, large animals tend to become smaller and small animals tend to become larger. The process was clearly occurring on Flores, whose fauna includes giant rats and now-extinct miniature elephants. What captures the imagination is that dwarfing might have occurred in humans, who often buffer themselves from natural selection through cultural means such as tool production and fire-making, both evident at Liang Bua ${ }^{2}$.

The Liang Bua finds have generated controversy. Two alternative hypotheses, yet to be published in the peer-reviewed literature, have been proposed. One is that the LB1 skeleton is a pygmy human, not a new hominid species. The other is that LB1 is a human who suffered from a form of microcephaly, a pathological condition characterized by an abnormally small brain and head, and which can also cause dwarfism ${ }^{6,7}$.

Morwood and colleagues ${ }^{3}$ now counter some of these claims with evidence recovered during excavations in 2004. The material substantially expands the sample attributed to $H$. floresiensis, and provides additional details about the proposed species. The new fossils consist of the right humerus, radius and ulna of the LB1 skeleton, the mandible of a second individual (LB6), and assorted other remains including two tibiae, a femur, two radii, an ulna, a scapula, a vertebra, and various toe and finger bones. The researchers think that the sample includes the remains of at least nine individuals.

The analysis ${ }^{3}$ focuses on the new mandible (LB6), a new tibia (LB8) and the LB1 skeleton's reunited arm bones. Of the many details, several merit special attention. First, the new mandible is extraordinarily similar to the first one. They almost certainly belong to the same species. Both mandibles share distinctive dental features, and they lack chins - a chin being a unique feature of all Homo sapiens regardless of their stature, including most microcephalics (Fig. 1, overleaf). In addition, the new tibia and arm-bone fossils not only confirm that the Liang Bua hominids were short, about a metre tall, but also indicate that they had relatively long arms. In many ways, the LB1 skeleton's body proportions are less like any adult human's, including adult pygmies, than those of an australopithecine - an earlier hominid lineage, thought to have been confined to Africa.

Another notable point is that the Liang Bua fossils come from a lengthy temporal span during which the cave's inhabitants were hunting animals, producing stone tools and 


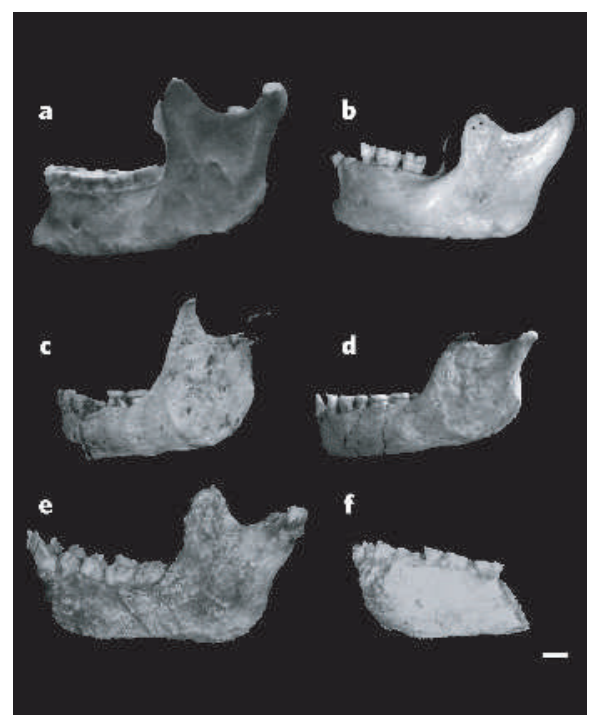

Figure 1 | Comparison of mandibles. a, Homo sapiens from Upper Cave Zhoukoudian, China; b, a microcephalic H. sapiens from Mauritius (Peabody Museum, Harvard Univ.); c, Homo floresiensis (LB1); d, H. floresiensis (LB6); e, early African Homo erectus (KNM-WT 15000); f, Australopithecus afarensis (Laetoli Hominid 4). The Liang Bua mandibles lack a chin, unlike those of $H$. sapiens, including the microcephalic example shown here. Lack of a chin is an ancestral feature of hominids, and is also a characteristic of $H$. erectus and $A$. afarensis. Scale bar, $1 \mathrm{~cm}$.

making fire. Although the original LB1 skeleton is estimated to be 18,000 years old, a child's radius was found in deposits estimated to be 12,000 years old, and the new mandible is estimated to be 15,000 years old; other finds may be as old as 95,000 years ${ }^{2,3}$.

The fossils also all seem to be similarly small, refuting the contention that the LB1 skeleton was simply an aberrantly dwarfed, pathological specimen. If they were pathological, then the Liang Bua fossils would have had to have come from a population of short, microcephalic humans that survived for a long time, or one that was susceptible to high frequencies of microcephaly and dwarfism. Such possibilities strain credulity; moreover, a three-dimensional analysis of the LB1 braincast $^{8}$ found the brain to be unlike a microcephalic's, and more like that of $H$. erectus than H. sapiens. Microcephaly, however, can have many causes ${ }^{9}$, and further studies that use larger sample sizes and analyse a wide range of syndromes will be necessary to test the hypothesis completely.

All in all, it seems reasonable for Morwood and colleagues ${ }^{3}$ to stick to their original hypothesis that $H$. floresiensis is a new species. But they are less certain about whether it evolved from $H$. erectus or from some other species, and raise the possibility that the species derives from an unknown small-bodied hominid, more primitive than $H$. erectus and with australopithecine-like body proportions. This seems unlikely, given the many derived features characteristic of Homo present in
H. floresiensis. However, the variability evident in new fossil material of early Homo from Georgia $^{10}$ and Kenya ${ }^{11}$ underscores just how little we know about diversity within the human genus.

What is needed to test the various proposed hypotheses and convince the sceptics? As always, more fossils would help. Because Flores was inhabited at least 800,000 years $\mathrm{ago}^{4}$, it will be useful to find older fossils and see if they look like $H$. erectus, or something else. Further, if the island-dwarfing hypothesis is correct, then the island's earliest inhabitants should be larger than the Liang Bua fossils; and if dwarfing occurred gradually, then it might even be possible to find fossils intermediate in size and shape between $H$. floresiensis and its ancestor. More evidence on when $H$. sapiens first arrived on Flores is also needed.

Such fossils may not be there to be found, however, and testing evolutionary hypotheses from even a well-sampled fossil record poses many challenges. One obvious avenue is to apply morphometric methods that analyse three-dimensional shape independently of size, to test whether the fossils are scaled down versions of $H$. erectus, $H$. sapiens or something else $^{12}$. Many syndromes can cause microcephaly and dwarfism ${ }^{9}$, and they all need to be considered. Finally, it would be interesting to find out how the hypothesized size reductions on Flores differ from those of other dwarfed island mammals.

The finds from Liang Bua are not only astonishing, but also exciting because of the questions they raise. More analyses that may lead to answers are on the way, despite an unfortunate custody dispute over the fossils that led to some being damage ${ }^{13}$. Eventually, we might even reach a consensus about the nature and origins of $H$. floresiensis, particularly after the data become available to the general scientific community.

Daniel E. Lieberman is at the Peabody Museum, Harvard University, 11 Divinity Avenue,

Cambridge, Massachusetts 02138, USA.

e-mail:danlieb@fas.harvard.edu

1. Brown, P. et al. Nature 431, 1055-1061 (2004).

2. Morwood, M. J. et al. Nature 431, 1087-1091 (2004).

3. Morwood, M. J. et al. Nature 437, 1012-1017 (2005).

4. Morwood, M. J., O'Sullivan, P. B., Aziz, F. \& Raza, A. Nature 392, 173-176 (1998)

5. Foster, J. B. Nature 202, 234-235 (1964).

6. Henneberg, M. \& Thorne, A. Before Farming 4, 2-3 (2004)

7. Dalton, R. Nature 434, 432-434 (2005).

8. Falk, D. et al. Science 308, 242-245 (2005).

9. Gilbert, S. L., Dobyns, W. B. \& Lahn, B. T. Nature Rev. Genet. 6, 581-590 (2005).

10. Vekua, A. et al. Science $\mathbf{2 9 7}, \mathbf{8 5 - 8 9}$ (2002)

11. Spoor, F., Leakey, L. N. \& Leakey, M. G. Am. J. Phys Anthropol. Suppl. 40, 195-196 (2005).

12. Zelditch, M. L., Swiderski, D. L., Sheets, H. D. \& Fink, W. L. Geometric Morphometrics for Biologists: A Primer (Elsevier, San Diego, 2004)

13. Culotta, E. Science 307, 1848 (2005).

\title{
PLANETARY SCIENCE
}

\section{The impact of Deep Impact}

\author{
Paul D. Feldman
}

\section{A good look at the Deep Impact cometary encounter was taken by the Rosetta mission, itself on the way to a rendezvous with a comet in 2014. So what is a comet - icy dustball or dusty iceball?}

NASA's Deep Impact mission aimed to bring a spacecraft weighing 362 kilograms into collision with the periodic comet 9P/Tempel 1 on 4 July 2005. The mission was, by all accounts, a smashing success: the images returned by both the impactor, which showed the first detailed views of a cometary nucleus from just before collision, and the mother-ship, showing the impact and its immediate after-effects (Fig. 1), are truly spectacular ${ }^{1}$.

The scientific success of Deep Impact depended not just on the accuracy of the spacecraft's controllers, but also on an extensive network of Earth- and space-based observers that appropriated almost all of the planet's astronomical resources to study the effects of the collision in every region of the electromagnetic spectrum ${ }^{2}$. The first results from this wealth of data have already been presented at conferences in Búzios, Brazil ${ }^{3}$, and Cambridge, $\mathrm{UK}^{4}$. On page 987 of this issue, Küppers et al. ${ }^{5}$ present observations of Deep
Impact from the European Space Agency's Rosetta spacecraft, launched on 2 March 2004. This spacecraft is itself on a ten-year voyage to another periodic comet, 67P/ChuryumovGerasimenko, where it will orbit the comet's nucleus and, in November 2014, deposit a lander to probe the composition and physical nature of its surface and immediate subsurface.

Comets are of interest because their composition is expected to reflect conditions that were prevalent when the Solar System was formed. So far, only the make-up of a comet's enveloping coma is known to any great extent. Within about $3 \mathrm{AU}$ of the Sun (1 AU, or astronomical unit, is the distance from Earth to the Sun), the gaseous component of this unbound atmosphere is dominated by water that has been sublimated (converted directly from ice to vapour) from the surface of the comet's nucleus by the warming effect of the Sun. Dust grains are also present in the coma and tail, 